Tohoku J. Exp. Med., 2008, 216, 353-361

\title{
High Prevalence of Prehypertension Is Associated with the Increased Body Mass Index in Community-Dwelling Japanese
}

\author{
Ryuichi Kawamoto, ${ }^{1}$ Katsuhiko Kohara, ${ }^{2}$ Yasuharu Tabara ${ }^{2}$ and \\ Tetsuro MiKI ${ }^{2}$ \\ ${ }^{1}$ The Department of Internal Medicine, Nomura Municipal Hospital, Ehime, Japan \\ ${ }^{2}$ The Department of Geriatric Medicine, Ehime University School of Medicine, Ehime, Japan
}

Hypertension and obesity are likely the most common disease in Japan. It has been reported that subjects with prehypertension (systolic blood pressure [SBP] $120-139 \mathrm{mmHg}$ and/ or diastolic blood pressure [DBP] $80-89 \mathrm{mmHg}$ ) have also an increased risk of cardiovascular disease; however, only limited data are available on the prevalence of prehypertension and its association with body weight. We performed a cross-sectional study to examine whether the status of body weight was associated with prehypertension. Study participants aged 19 to 90 years [1,207 men aged $60 \pm 15$ (mean \pm standard deviation) years and 1,634 women aged $63 \pm 12$ years] were randomly recruited for a survey at the community-based annual medical check-up. The prevalence of prehypertension was $27.3 \%$ in men and $23.9 \%$ in women. The levels of SBP and DBP increased, as body mass index (BMI) increased in both genders. In a multivariate-adjusted model, increasing BMI categories were positively associated with prehypertension. Especially in men, compared to participants with BMI of $<21.0 \mathrm{~kg} / \mathrm{m}^{2}$ (referent), the multivariate-odds ratio $(95 \% \mathrm{CI})$ of prehypertension was $1.90(1.17-3.09)$ in the $21.0-23.4 \mathrm{~kg} / \mathrm{m}^{2}$ group, $2.38(1.31-4.34)$ in the $23.5-24.9 \mathrm{~kg} / \mathrm{m}^{2}$ group, and $3.79(2.03-7.09)$ in the $\geq 25.0 \mathrm{~kg} / \mathrm{m}^{2}$ group. In conclusion, even subjects with mildly increased BMI $\left(21.0-24.9 \mathrm{~kg} / \mathrm{m}^{2}\right)$ had an increased risk of prehypertension in community-dwelling persons. It is time to pay more attention to excess bodyweight in preventing high blood pressure. — risk factor; body mass index; prehypertension; hypertension; community-dwelling persons.

Tohoku J. Exp. Med., 2008, 216 (4), 353-361.

(C) 2008 Tohoku University Medical Press

Hypertension is likely the most common disease in Japan and is strongly associated with an increased risk of cardiovascular disease (CVD). An increased risk of CVD mortality is present in persons with blood pressure levels as low as 115 $\mathrm{mmHg}$ systolic blood pressure (SBP) and 70 $\mathrm{mmHg}$ diastolic blood pressure (DBP), and the risk increases steadily with elevating blood pres- sure (Lewington et al. 2002). The most recent references for blood pressure classification in adults are the Seventh Report of the Joint National Committee on Prevention, Detection, Evaluation, and Treatment of High Blood Pressure (JNC-7) in 2003. In this guideline, people with SBP of 120 to $139 \mathrm{mmHg}$ and/or DBP of 80 to $89 \mathrm{mmHg}$ were categorized as having prehypertension

Received October 6, 2008; revision accepted for publication November 9, 2008.

Correspondence: Ryuichi Kawamoto, Department of Internal Medicine, Seiyo Municipal Nomura Hospital,

9-53 Nomura, Nomura-cho, Seiyo-city, Ehime 797-1212, Japan.

e-mail: rykawamo@ehime.med.or.jp 
(Chobanian et al. 2003). Prehypertension and even normal blood pressure frequently progress to clinical hypertension over several years, especially in older adults (Vasan et al. 2001). The incremental relationship between blood pressure and cardiovascular disease (CVD) risk is continuous and consistent (Qureshi et al. 2005; Nakamura et al. 2006; Gu et al. 2008). Prehypertension is associated with an increased risk of major CVD events, thus lifestyle modification or even medical treatment is recommended for individuals with prehypertension (Lewington et al. 2002). However, the prevalence of prehypertension and associated risk factors in Japan is not clear.

Obesity is also a worldwide public health problem. Obesity increases the risk of cardiovascular disease, diabetes, hypertension, and dyslipidemia. However, few studies have examined the relationship between excess body weight and elevated blood pressure risk.

The aim of this study was to evaluate the distribution of blood pressure and the prevalence of prehypertension and its association with body weight, using cross-sectional data from rural community-dwelling Japanese persons.

\section{Materials ANd Methods}

\section{Subjects}

Participants were recruited at the time of their annual health examination in a rural town with a total population of 11,136 (as of April 2002) located in Ehime prefecture, Japan, in 2002. Among 9,133 adults aged 19 to 90 years in this population, a random sample of 3,164 $(34.6 \%)$ subjects was enrolled. Baseline clinical characteristics including anthropometric parameters were obtained from the subject's personal health records evaluated medical check-up. Other characteristics e.g., smoking and alcohol habit, and medication, were investigated by individual interviews using a structured questionnaire. Information on medical history, present conditions, and medications was obtained by interview. And the final study sample included 2,841 eligible persons. The Ethics Committee of Ehime University School of Medicine approved all procedures, and each participant provided informed consent for the procedure.

\section{Evaluation of risk factors}

We measured the participants' height without foot- wear and weight in light clothing and calculated their body mass index (BMI) as weight in kilograms divided by the square of height in meters. Participants with BMI $>30 \mathrm{~kg} / \mathrm{m}^{2}$ were included (37 subjects). Body mass index was subdivided into four categories as follows: BMI-1 (underweight), $<21.0 \mathrm{~kg} / \mathrm{m}^{2}$; BMI-2 (lower normal weight), $21.0-23.4 \mathrm{~kg} / \mathrm{m}^{2}$; BMI-3 (upper normal weight), $23.5-24.9 \mathrm{~kg} / \mathrm{m}^{2}$; BMI-4 (overweight), $\geq 25.0$ $\mathrm{kg} / \mathrm{m}^{2}$. We measured blood pressure in the right upper arm of participants in a sedentary position using an automatic oscillometric blood pressure recorder (BP-103i; Colin, Aichi, Japan) while the subjects were seated after having rested for at least $5 \mathrm{~min}$. Appropriate cuff bladder size was determined at each visit based on arm circumference. Normotension was defined as not being on antihypertensive medication and having of SBP $<120$ $\mathrm{mmHg}$ and $\mathrm{DBP}<80 \mathrm{mmHg}$. Prehypertension was defined as not being on antihypertensive medication and having a SBP of 120 to $139 \mathrm{mmHg}$ and/or DBP 80 to 89 $\mathrm{mmHg}$. Hypertension was defined as $\mathrm{SBP} \geq 140 \mathrm{mmHg}$ and/or DBP $\geq 90 \mathrm{mmHg}$, and also if the individual was on antihypertensive medication (Chobanian et al. 2003). Cigarette smoking was quantified based on daily consumption and duration of smoking. Fasting total cholesterol (T-C), triglycerides (TG), high-density lipoprotein cholesterol (HDL-C), fasting blood glucose (FBG), creatinine (enzymatic method), and uric acid were measured during fasting. Low-density lipoprotein cholesterol (LDL-C) levels were calculated by the Friedewald formula (Friedewald et al. 1972). Participants with TG levels $\geq 400 \mathrm{mg} / \mathrm{dL}$ were excluded ( 24 cases). The presence of diabetes and CVD was defined as a history of treatment for diabetes and CVD. Estimated glomerular filtration ratio (eGFR) was calculated with the following equation: $\mathrm{eGFR}=194 \times \mathrm{Cr}^{-1.094} \times \mathrm{Age}^{-0.287} \times 0.739$ (if female) (Levey et al. 2006; The Japanese Society of Nephrology 2007).

\section{Statistical analysis}

Statistical analysis was performed using SPSS 10.0J (Statistical Package for Social Science, Inc., Chicago, IL, USA). All values are expressed as mean \pm standard deviation (s.D.), unless otherwise specified. Data for smoking status and TG were skewed, and were log-transformed for multivariate analysis. Differences based on blood pressure status were analyzed by Mann-Whitney U tests or the chi-square $\left(\chi^{2}\right)$ tests. Correlations between various characteristics and BMI were determined using Pearson's correlation test. Logistic regression analyses 
were used to test significant factors of prehypertension (versus normotension) and hypertension status (versus normotension + prehypertension), with prehypertension and hypertension serving as the dichotomous outcome variable and age, BMI, smoking status, drinking status, antihypertensive medication, lipids, antilipidemic medication, FBG, diabetes, uric acid, and eGFR. A value of $p<0.05$ was considered significant.

\section{RESULTS}

Subject background factors categorized by sex

The 2,841 participants included 1,207 men aged $60 \pm 15$ years and 1,634 women aged $63 \pm$ 15 years. Among them, the prevalence of prehypertension and hypertension was $27.3 \%$ and $56.3 \%$ in men, and $23.9 \%$ and $54.7 \%$ in women. The prevalence of prehypertension decreased with increasing age and the prevalence of hypertension increased with increasing age in male and female subjects (Fig. 1). Table 1 shows the background characteristics of subjects according to sex. Smoking status, drinking status, DBP, TG, FBG, serum creatinine, uric acid levels and prevalence of CVD were higher in men than women, but age, T-C, HDL-C, and LDL-C were higher in women than in men. There were no inter-group differences in BMI, SBP, prevalence of diabetes and
eGFR.

Characteristics of subjects categorized by sex and blood pressure status

Table 2 shows the value of each background factor categorized by sex and blood pressure status. In men, age, BMI, presence of antihypertensive medication, T-C, TG, FBG, prevalence of diabetes, serum creatinine and uric acid, and prevalence of CVD were higher in subjects with prehypertension and hypertension than those with normotension, but smoking status and eGFR were lower in subjects with hypertension. In women, age, BMI, presence of antihypertensive medication, T-C, TG, LDL- C, presence of antilipidemic medication, FBG, serum creatinine, uric acid and prevalence of CVD were higher in subjects with prehypertension and hypertension than those with normotension, but smoking status, drinking status, HDL-C and eGFR were lower.

\section{Correlation between body mass index and} blood pressure by sex

By study design, these subjects are characteristic of the Japanese population with a BMI of 15.2 to $38.8 \mathrm{~kg} / \mathrm{m}^{2}$ in men and 14.2 to $41.4 \mathrm{~kg} / \mathrm{m}^{2}$

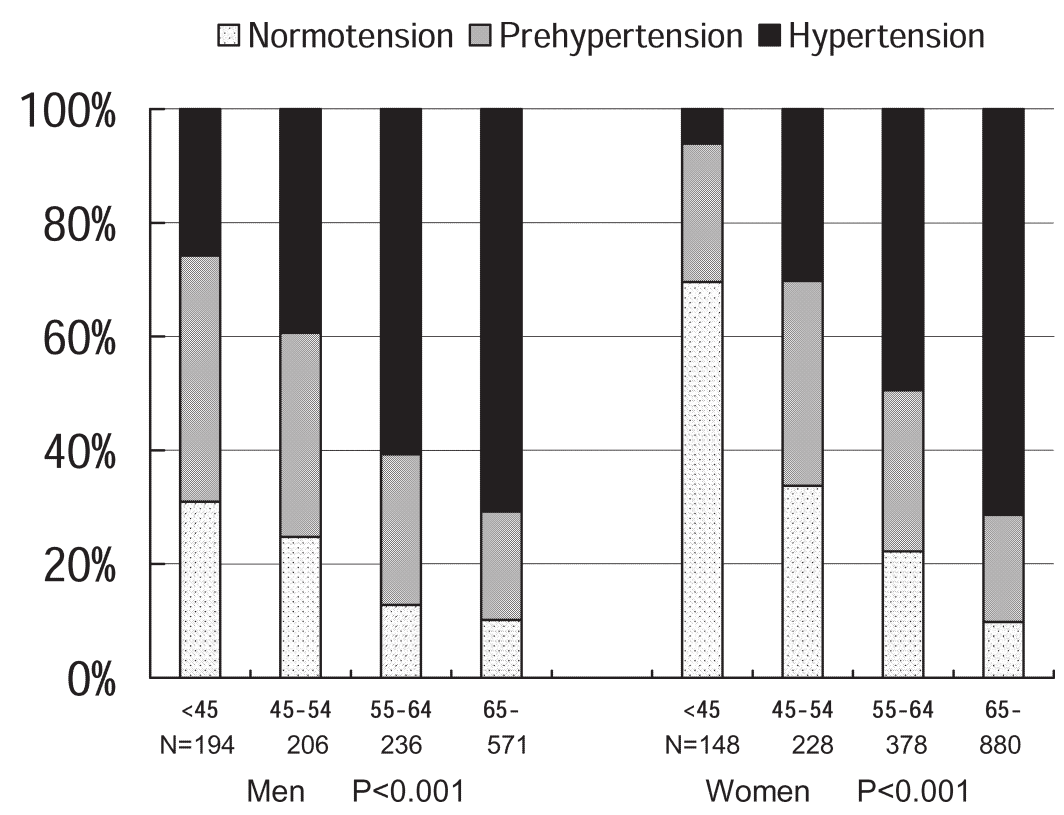

Fig. 1. Prevalence of each blood pressure status by age and gender $* P$-value; $\chi^{2}$ test. 
in

TABLE 1. Characteristics of subjects categorized by sex.

\begin{tabular}{|c|c|c|c|}
\hline Characteristics & $\operatorname{Men}(N=1,207)$ & Women $(N=1,634)$ & $P$-value* \\
\hline Age (years) & $60 \pm 15$ & $63 \pm 12$ & $<0.001$ \\
\hline Body mass index $x^{\dagger}\left(\mathrm{kg} / \mathrm{m}^{2}\right)$ & $23.5 \pm 3.1$ & $23.4 \pm 3.4$ & 0.288 \\
\hline Smoking status (pack year) $^{\ddagger}$ & $12(0-31)$ & 0 & $<0.001$ \\
\hline Drinking status, $\mathrm{N}(\%)$ & $1,015(84.1)$ & $544(33.3)$ & $<0.001$ \\
\hline Systolic blood pressure (mmHg) & $139 \pm 21$ & $138 \pm 23$ & 0.260 \\
\hline Diastolic blood pressure (mmHg) & $83 \pm 12$ & $80 \pm 12$ & $<0.001$ \\
\hline Antihypertensive medication, N (\%) & $315(26.1)$ & $455(27.8)$ & 0.306 \\
\hline Total cholesterol (mg/dL) & $191 \pm 35$ & $209 \pm 33$ & $<0.001$ \\
\hline Triglycerides (mg/dL) & $100(73-147)$ & $93(69-130)$ & $<0.001$ \\
\hline HDL cholesterol (mg/dL) & $58 \pm 15$ & $64 \pm 15$ & $<0.001$ \\
\hline LDL cholesterol (mg/dL) & $107 \pm 34$ & $124 \pm 30$ & $<0.001$ \\
\hline Antilipidemic medication, $\mathrm{N}(\%)$ & $50(4.2)$ & $110(6.7)$ & 0.004 \\
\hline Fasting blood glucose (mg/dL) & $103 \pm 28$ & $98 \pm 24$ & $<0.001$ \\
\hline Diabetes & $47(3.9)$ & $63(3.9)$ & 1.000 \\
\hline Serum creatinine $(\mathrm{mg} / \mathrm{dL})$ & $0.80 \pm 0.18$ & $0.61 \pm 0.14$ & $<0.001$ \\
\hline Serum uric acid (mg/dL) & $6.0 \pm 1.4$ & $4.5 \pm 1.1$ & $<0.001$ \\
\hline Estimated GFR & $80.7 \pm 17.5$ & $79.6 \pm 18.0$ & 0.139 \\
\hline Cardiovascular disease, $\mathrm{N}(\%)$ & $122(10.2)$ & $122(7.5)$ & 0.015 \\
\hline
\end{tabular}

Data presented are mean \pm standard deviation. Data for smoking status and triglycerides were skewed and are presented as median (interquartile range). Body mass index was calculated using weight in kilograms divided by the square of the height in meters. ${ }^{5}$ Smoking status: daily consumption (pack) $\times$ duration of smoking (year). HDL, high-density lipoprotein; LDL, low-density lipoprotein; GFR, Glomerular Filtration Rate. Estimated GFR $=194 \times \mathrm{Cr}^{-1.094} \times \mathrm{Age}^{-0.287} \times 0.739$ (if female). $* P$-value for comparison between men and women; $* P$-value; Mann-Whitney $\mathrm{U}$ test or $\chi^{2}$ test.

women. In men and women, BMI significantly correlated with SBP $(r=0.206$ and $r=0.256$, respectively) and DBP $(r=0.258$ and $r=0.271$, respectively). Presence of antihypertensive and antilipidemic medication and prevalence of CVD were significantly lower in subjects with lowest category of BMI than those with other category (data not shown).

Odds ratio of prehypertension and hypertension by BMI categories

Table 3 shows the odds ratios (ORs) $\{95 \%$ confidence interval $(\mathrm{CI})\}$ of prehypertension and hypertension with increasing BMI category. Increasing BMI categories were positively associated with prehypertension and hypertension in both genders in a univariate model, and especially in men in a multivariate-adjusted model.
Compared to male subjects with a BMI of $<21.0$ $\mathrm{kg} / \mathrm{m}^{2}$ (referent), the multivariate-OR $(95 \% \mathrm{CI})$ of prehypertension was $1.90(1.17-3.09)$ in the $21.0-23.4 \mathrm{~kg} / \mathrm{m}^{2}$ group, $2.38(1.31-4.34)$ in the $23.5-24.9 \mathrm{~kg} / \mathrm{m}^{2}$ group, and 3.79 (2.03-7.09) in the $\geq 25.0 \mathrm{~kg} / \mathrm{m}^{2}$ group. Moreover, the multivariate-OR $(95 \% \mathrm{CI})$ of hypertension was 1.88 $(1.23-2.86)$ in the $21.0-23.4 \mathrm{~kg} / \mathrm{m}^{2}$ group, 2.15 $(1.33-3.48)$ in the $23.5-24.9 \mathrm{~kg} / \mathrm{m}^{2}$ group, and 3.61 $(2.25-5.78)$ in the $\geq 25.0 \mathrm{~kg} / \mathrm{m}^{2}$ group.

\section{Discussion}

In this cross-sectional, population-based study, we set out to determine the prevalence of prehypertension and hypertension, as defined by JNC-7 criteria (Chobanian et al. 2003), and its association with body weight. This study showed that prehypertension and hypertension are 


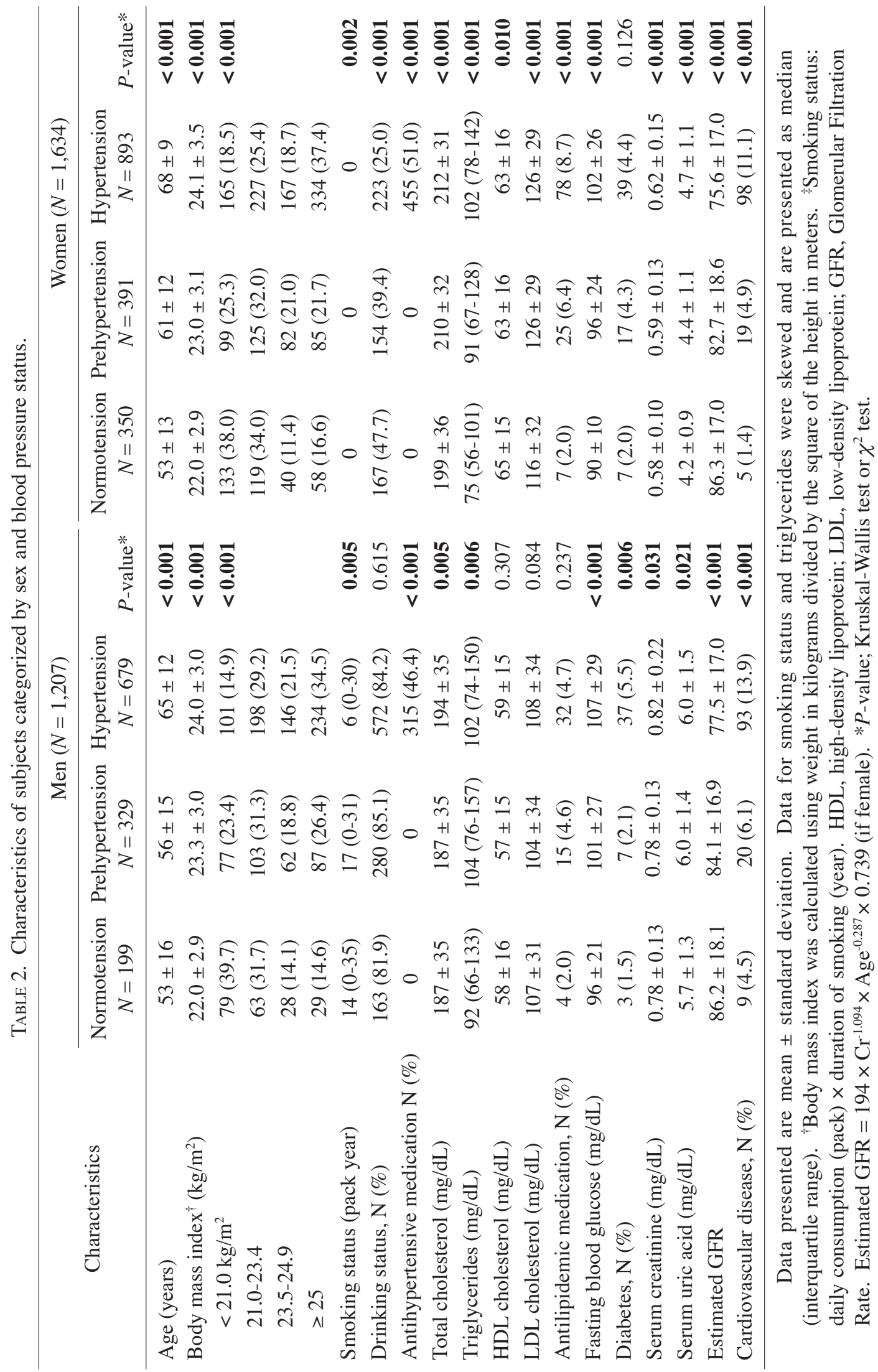


R. Kawamoto et al.

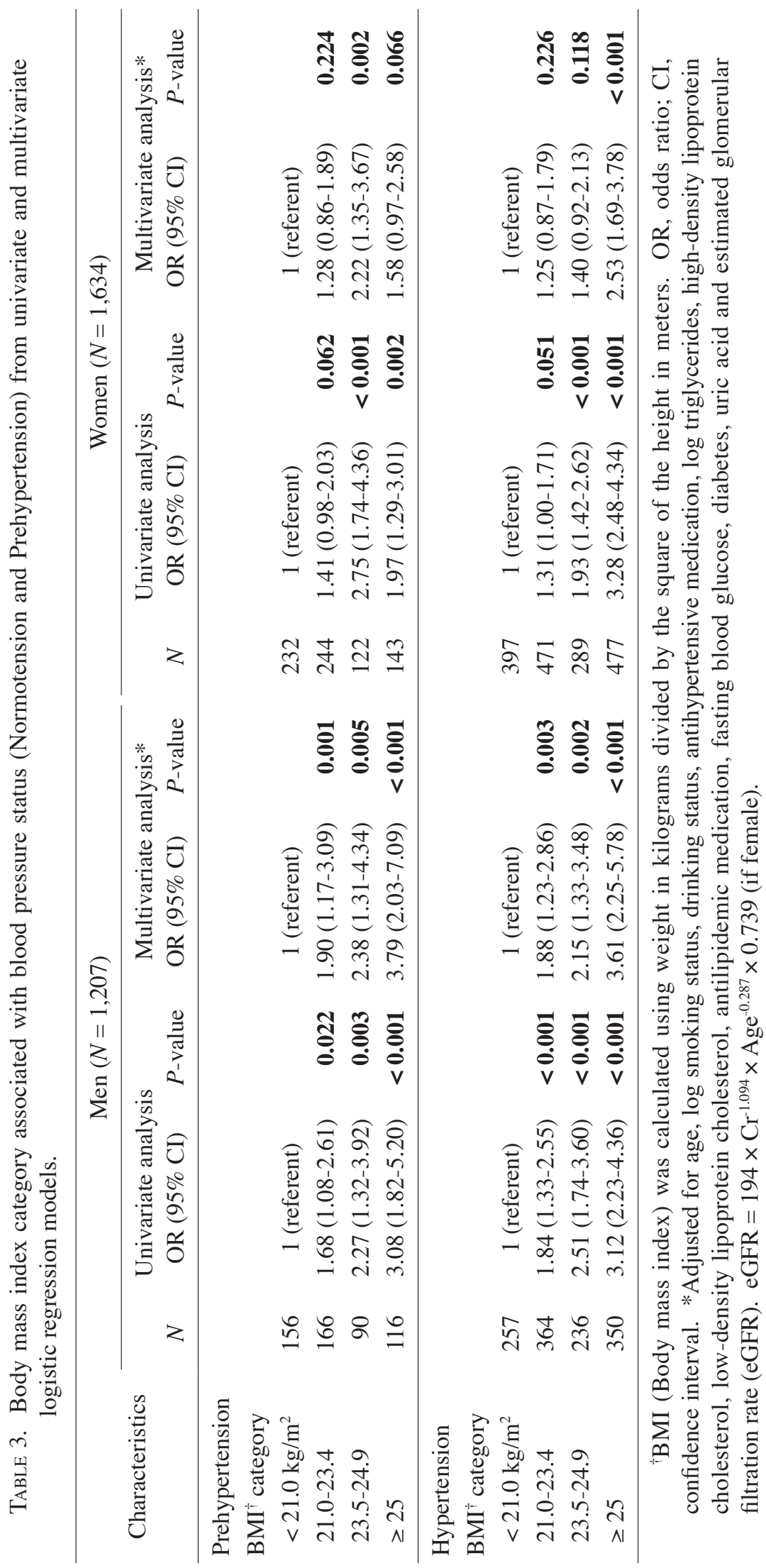



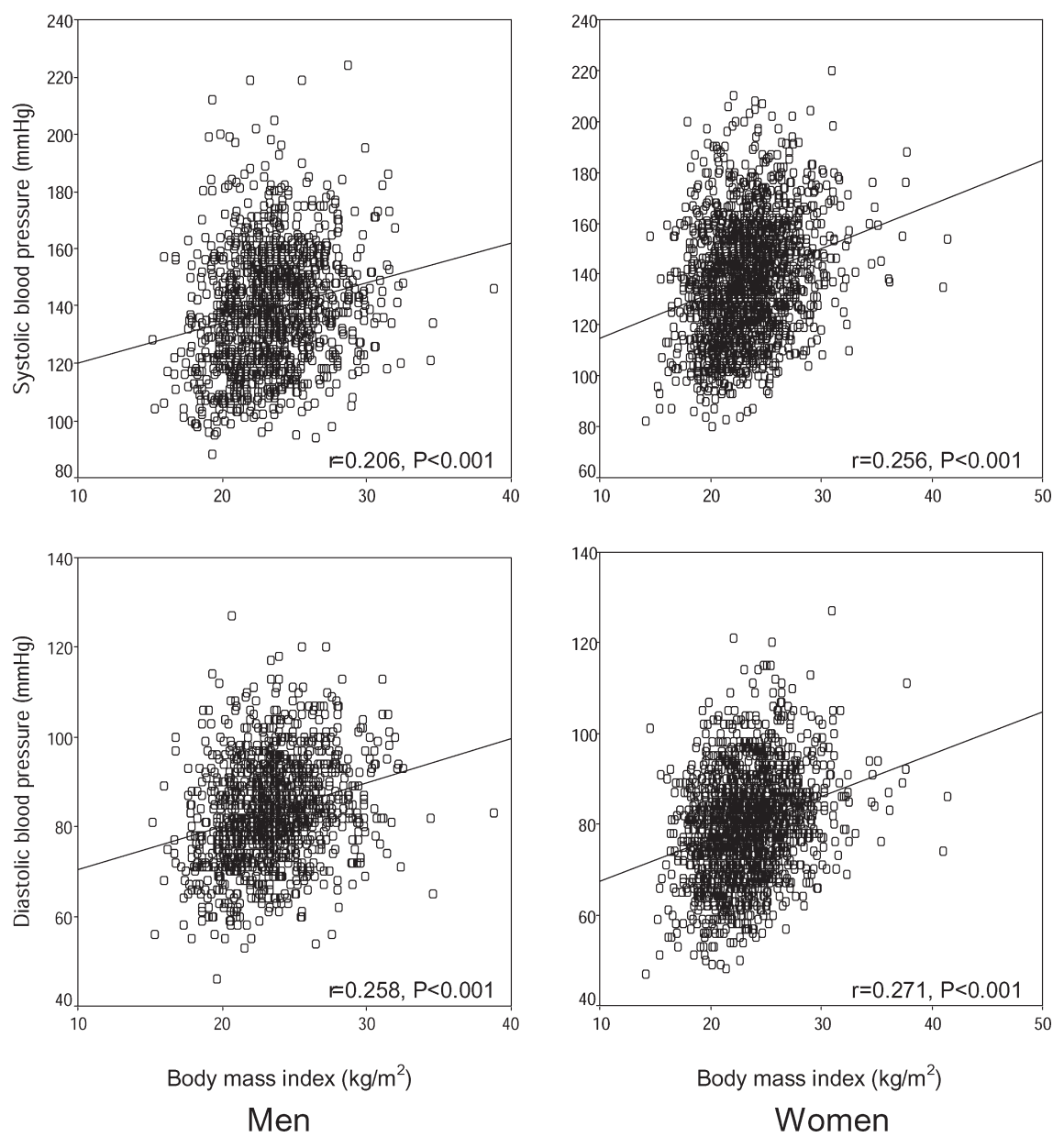

Fig. 2. Correlation between body mass index and blood pressure by sex. In men and women, BMI significantly correlated with SBP $(r=0.206$ and $r=0.256$, respectively) and DBP $(r=0.258$ and $r=$ 0.271 , respectively).

extremely common, affecting more than half of male subjects $(83.5 \%)$ and female subjects (78.6\%), and persons with prehypertension and hypertension had a higher prevalence of other risk factors for atherosclerotic disease, including increased BMI, dyslipidemia, and FBG, but not smoking, than did persons with normotension. The prevalence of prehypertension significantly decreased with increasing age because many participants in the older group aged $\geq 65$ years had hypertension $(71.1 \%)$. Furthermore, the prevalence was significantly higher in the upper normal weight or overweight individuals than in the lower normal weight.

Our study found an overall prehypertension prevalence rate of $25.3 \%$ in rural Japanese adults, a similar level to Taiwanese (Tsai et al. 2005) and American adults (Greenlund et al. 2004). The prevalence of prehypertension decreased with increasing age and was significantly greater in men than in women, which was similar to a study with Chinese adults (Sun et al. 2007). In our study, increasing BMI categories were positively associated with prehypertension and hypertension. Similar results were found in a community-based, cross-sectional study in Taiwanese (Tsai et al. 2005), and multivariable logistic regression revealed that age $(\mathrm{OR}, 1.01 ; 95 \% \mathrm{CI}, 1.00-1.03)$ and BMI (OR, 1.11; 95\% CI, 1.05-1.17) were predictors of prehypertension status in men. For women, age (OR, 1.03; 95\% CI, 1.02-1.04), waist circumference (OR, 1.03; 95\% CI, 1.01-1.05), and 
triglycerides (OR, 1.00; 95\% CI, 1.00-1.01) were determinants of prehypertension (Tsai et al. 2005). Also in a cross-sectional study in Israel, body weight was strongly and linearly associated with blood pressure and accounted for $8 \%$ to $10 \%$ of blood pressure variance (Sharabi et al. 2004).

In this study, $20.0 \%$ and $23.9 \%$ of men with prehypertension, and $23.9 \%$ and $36.1 \%$ of women with prehypertension were upper normal weight (BMI, 23.5-24.9 kg/m ${ }^{2}$ ) and overweight (BMI, $\geq$ $25 \mathrm{~kg} / \mathrm{m}^{2}$ ), respectively. Among Japanese workers, $31.2 \%$ of men and $19.5 \%$ of women are overweight or obese (Inoue et al. 2007). Moreover, these prevalences are expected to increase in Japan in the future. Excess bodyweight could therefore increase the burden of prehypertension in such populations. The long-term effect of weight reduction could lower the odds of hypertension by $77 \%$ (He et al. 2000). The prehypertension status highlights the need for early intervention to lower blood pressure through lifestyle modification (Mitsui et al. 2008).

The mechanisms that lead to prehypertension and hypertension in individuals with excess bodyweight are not completely understood. Several previous studies showed that being obese or overweight increased the risk of cardiovascular disease, diabetes, hypertension, dyslipidemia, and renal dysfunction (Mokdad et al. 2003; Qureshi et al. 2005; $\mathrm{Gu}$ et al. 2008). The relationship between increased BMI and blood pressure may incorporate other non-traditional risk factors not examined in this report, including increased C-reactive protein (Ridker et al. 2002), amyloid A (Poitou et al. 2006), hyperlipidemia (Qureshi et al. 2005; Gu et al. 2008), cytokines (Honda et al. 2006), homocysteine (Homocysteine Studies Collaboration 2002), oxidative stress (Drüeke et al. 2002), hyperleptinemia (Mathew et al. 2007), increased sympathetic activity (Masuo et al. 2000), renal hyperfiltration (Knight and Imig 2007) and gamma-glutamyl transferase activity (Kawamoto et al. 2008) caused by insulin resistance, and the renin-angiotensin system (Engeli et al. 1999). All these risk factors result in atherosclerosis, and prehypertension and hypertension may be complicated by both the severity and duration of atherosclerosis, and vice versa.

Our cross-sectional study design does not eliminate potential causal relationships between BMI and blood pressure. The prevalence of blood pressure categories is based on single blood pressure measurement. We could not rule out onetime hypertension and white-coat hypertension. There still remain important problems on the cumulative effects of excess bodyweight over several decades, the effect of weight-change periods or past maximum weight, and interactions with other risk factors (Ben-Shlomo and Kuh 2002). Therefore, the demographics and referral source may limit generalizability.

In conclusion, the present study showed that even subjects with mildly increased BMI (21.0$24.9 \mathrm{~kg} / \mathrm{m}^{2}$ ) had an increased risk of prehypertension and hypertension in the general population. The underlying mechanism seems to be independent from traditional cardiovascular risk factors such as age, dyslipidemia, and diabetes. For community-dwelling healthy persons, prospective population-based studies are needed to investigate the mechanisms underlying this association to determine whether intervention, such as effective lifestyle modifications that decrease bodyweight, in adult populations will decrease risks.

\section{Acknowledgment}

This work was supported in part by a grantin-aid from the Foundation for Development of Community (2008).

\section{References}

Ben-Shlomo, Y. \& Kuh, D. (2002) A life course approach to chronic disease epidemiology: conceptual models, empirical challenges and interdisciplinary perspectives. Int. J. Epidemiol., 31, 285-293.

Chobanian, A.V., Bakris, G.L., Black, H.R., Cushman, W.C., Green, L.A., Izzo, J.L. Jr., Jones, D.W., Materson, B.J., Oparil, S., Wright, J.T. Jr. \& Roccella, E.J. (2003) Joint National Committee on Prevention, Detection, Evaluation, and Treatment of High Blood Pressure. National Heart, Lung, and Blood Institute; National High Blood Pressure Education Program Coordinating Committee: The seventh report of the Joint National Committee on Prevention, Detection, Evaluation, and Treatment of High Blood Pressure. Hypertension, 42, 1206-1252.

Drüeke, T., Witko-Sarsat, V., Massy, Z., Descamps-Latscha, B., Guerin, A.P., Marchais, S.J., Gausson, V. \& London, G.M. (2002) Iron therapy, advanced oxidation protein products, and carotid artery intima-media thickness in end-stage renal 
disease. Circulation, 106, 2212-2217.

Engeli, S., Gorzelniak, K., Kreutz, R., Runkel, N., Distler, A. \& Sharma, A.M. (1999) Co-expression of renin-angiotensin system genes in human adipose tissue. J. Hypertens., 17, 555-560.

Friedewald, W.T., Levy, R.I. \& Fredrickson, D.S. (1972) Estimation of the concentration of low-density lipoprotein cholesterol in plasma, without use of the preparative ultracentrifuge. Clin. Chem., 18, 499-502.

Greenlund, K.J., Croft, J.B. \& Mensah, G.A. (2004) Prevalence of heart disease and stroke risk factors in persons with prehypertension in the United States, 1999-2000. Arch. Intern. Med., 164, 2113-2118.

Gu, Q., Burt, V.L., Paulose-Ram, R., Yoon, S. \& Gillum, R.F. (2008) High blood pressure and cardiovascular disease mortality risk among U.S. adults: the third National Health and Nutrition Examination Survey mortality follow-up study. Ann. Epidemiol., 18, 302-309.

He, J., Whelton, P.K., Appel, L.J., Charleston, J. \& Klag, M.J. (2000) Long-term effects of weight loss and dietary sodium reduction on incidence of hypertension. Hypertension, 35, 544-549.

Homocysteine Studies Collaboration (2002) Homocysteine and risk of ischemic heart disease and stroke: a meta-analysis. JAMA, 288, 2015-2022.

Honda, H., Qureshi, A.R., Heimbürger, O., Barany, P., Wang, K., Pecoits-Filho, R., Stenvinkel, P. \& Lindholm, B. (2006) Serum albumin, C-reactive protein, interleukin 6, and fetuin-A as predictors of malnutrition, cardiovascular disease, and mortality in patients with ESRD. Am. J. Kidney Dis., 47, 139-148.

Inoue, M., Toyokawa, S., Miyoshi, Y., Miyano, Y., Suzuki, T., Suyama, Y., Inoue, K. \& Kobayashi, Y. (2007) Degree of agreement between weight perception and body mass index of Japanese workers: MY Health Up Study. J. Occup. Health, 49, 376-381.

Kawamoto, R., Kohara, K., Tabara, Y., Kusunoki, T., Otsuka, N. \& Miki, T. (2008) Association between serum gammaglutamyl transferase level and prehypertension among community-dwelling men. Tohoku J. Exp. Med., 216, 213-221.

Knight, S.F. \& Imig, J.D. (2007) Obesity, insulin resistance, and renal function. Microcirculation, 14, 349-362.

Levey, A.S., Coresh, J., Greene, T., Stevens, L.A., Zhang, Y.L., Hendriksen, S., Kusek, J.W. \& Van Lente, F. (2006) Chronic Kidney Disease Epidemiology Collaboration: Using standardized serum creatinine values in the modification of diet in renal disease study equation for estimating glomerular filtration rate. Ann. Intern. Med., 145, 247-254.

Lewington, S., Clarke, R., Qizilbash, N., Peto, R. \& Collins, R. (2002) Prospective Studies Collaboration: Age-specific relevance of usual blood pressure to vascular mortality: a meta-analysis of individual data for one million adults in
61 prospective studies. Lancet, 360, 1903-1913.

Masuo, K., Mikami, H., Itoh, M., Ogihara, T. \& Tuck, M.L. (2000) Sympathetic activity and body mass index contribute to blood pressure levels. Hypertens. Res., 23, 303-310.

Mathew, B., Patel, S.B., Reams, G.P., Freeman, R.H., Spear, R.M. \& Villarreal, D. (2007) Obesity-hypertension: emerging concepts in pathophysiology and treatment. Am. J. Med. Sci., 334, 23-30.

Mitsui, T., Shimaoka, k., Tsuzuku, S., Kajioka, T. \& Sakakibara, H. (2008) Gentle exercise of 40 minutes with dietary counseling is effective in treating metabolic syndrome. Tohoku J. Exp. Med., 215, 355-361.

Mokdad, A.H., Ford, E.S., Bowman, B.A., Dietz, W.H., Vinicor, F., Bales, V.S. \& Marks, J.S. (2003)_Prevalence of obesity, diabetes, and obesity-related health risk factors, 2001. JAMA, 289, 76-79.

Nakamura, Y., Yamamoto, T., Okamura, T., Kadowaki, T., Hayakawa, T., Kita, Y., Saitoh, S., Okayama, A. \& Ueshima, H. (2006) The NIPPON DATA 80 Research Group: Combined cardiovascular risk factors and outcome: NIPPON DATA80, 1980-1994. Circ. J., 70, 960-964.

Poitou, C., Coussieu, C., Rouault, C., Coupaye, M., Cancello, R., Bedel, J.F., Gouillon, M., Bouillot, J.L., Oppert, J.M., Basdevant, A. \& Clément, K. (2006) Serum amyloid A. a marker of adiposity-induced low-grade inflammation but not of metabolic status. Obesity, 14, 309-318.

Qureshi, A.I., Suri, M.F., Kirmani, J.F., Divani, A.A. \& Mohammad, Y. (2005) Is prehypertension a risk factor for cardiovascular diseases? Stroke, 36, 1859-1863.

Ridker, P.M., Rifai, N., Rose, L., Buring, J.E. \& Cook, N.R. (2002) Comparison of C-reactive protein and low-density lipoprotein cholesterol levels in the prediction of first cardiovascular events. N. Engl. J. Med., 347, 1557-1565.

Sharabi, Y., Grotto, I., Huerta, M. \& Grossman, E. (2004) Susceptibility of the influence of weight on blood pressure in men versus women: lessons from a large-scale study of young adults. Am. J. Hypertens., 17, 404-408.

Sun, Z., Zheng, L., Wei, Y., Li, J., Zhang, X., Zhang, X., Liu, S., Xu, C., Li, J., Zhao, F., Hu, D. \& Sun, Y. (2007) Prevalence and risk factors of the rural adult people prehypertension status in Liaoning Province of China. Circ. J., 71, 550-553.

The Japanese Society of Nephrology (2007) Japanese version of GFR estimation. http://www.jsn.or.jp, Updated Oct, 29.

Tsai, P.S., Ke, T.L., Huang, C.J., Tsai, J.C., Chen, P.L., Wang, S.Y. \& Shyu, Y.K. (2005) Prevalence and determinants of prehypertension status in the Taiwanese general population. J. Hypertens., 23, 1355-1360.

Vasan, R.S., Larson, M.G., Leip, E.P., Kannel, W.B. \& Levy, D. (2001) Assessment of frequency of progression to hypertension in non-hypertensive participants in the Framingham Heart Study: a cohort study. Lancet, 358, 1682-1686. 